\title{
Theoretical Studies on Structures and Electronic State of Alkyl-Substituted Ethyl Cations
}

\author{
Toshiaki Shimasaki, ${ }^{1}$ Ken Nakayasu, ${ }^{2}$ Mitsuhiro Shibata, ${ }^{1}$ and Tatsuaki Yamaguchi ${ }^{1}$ \\ ${ }^{1}$ Department of Life and Environmental Sciences, Faculty of Engineering, Chiba Institute of Technology, \\ Narashino, Chiba 275-0016, Japan \\ ${ }^{2}$ Instrumental Analysis Division, Center for Supports to Research and Education Activities, Kobe University, \\ 1-1 Rokkodai-cho, Nada, Kobe 657-8501, Japan \\ Correspondence should be addressed to Toshiaki Shimasaki; tshima@sun.it-chiba.ac.jp
}

Received 17 May 2013; Accepted 10 July 2013

Academic Editor: Adriana Szeghalmi

Copyright (C) 2013 Toshiaki Shimasaki et al. This is an open access article distributed under the Creative Commons Attribution License, which permits unrestricted use, distribution, and reproduction in any medium, provided the original work is properly cited.

\begin{abstract}
This paper describes the gas phase structural details for a series of alkyl-substituted ethyl cations 1-11 by mainly natural bond orbital (NBO) analysis. For the simplest ethyl cation, two kinds of optimized structures (nonclassical 1 and classical 2) were found to have minima on the potential surface, and the nonclassical 1 was more stable than the corresponding classical $2 \mathrm{by} 1.19 \mathrm{kcal} / \mathrm{moL}$ at Møller-Plesset (MP) level calculations in the gas phase. The calculated values of Wiberg's bond index revealed that the central ethylic $C^{1}-C^{2}$ bonds of the nonclassical cations $1,6,7$, and 10 have $1.10-1.46$ bond multiplicities. The compliance constant $\left(C_{i i}\right)$ values indicated that the cation center $C^{1}$ of nonclassical 2-butyl cation $6(0.209 \AA / \mathrm{mdyn})$ acquires stronger hyperconjugative stabilization from $\mathrm{C}^{2}-\mathrm{R}^{3}(\mathrm{C}-\mathrm{H})$ bond than that of the nonclassical ethyl cation $\mathbf{1}(0.388 \AA / \mathrm{mdyn})$. Moreover, the gas phase stabilities for the alkyl-substituted ethyl cations 1-11 were also estimated by the hydride affinities based on isodesmic equations.
\end{abstract}

\section{Introduction}

The carbocations are not only important chemical species as intermediates in various organic reactions but also have been gathering much attention on their structure and electronic state [1]. Since the 1960s, Von Schleyer and coworkers have examined alkyl cations (carbonium ions), in part alkyl dications, by magic acid techniques [2]. Yannoni et al. have also studied the alkyl cation and especially revealed the structural details of tert-butyl cation (1,1-dimethylethyl cation) by NMR methods in 1989 [3].

Farrcaşiu et al. have theoretically investigated the conformations of carbocations and the reactions of their precursors with borane at high-level $a b$ initio calculations $[4,5]$. In 2007, Ricks and coworkers revealed that extraordinary stability of $\mathrm{C}_{4} \mathrm{H}_{9}{ }^{+}$species is brought about the charge distribution and hyperconjugation by means of IR spectral analysis [6]. Feng et al. reported the structural properties and energetics at high-level MO calculations on tert-butyl cation [7].
Structural details of ethyl cation, which is the most basic and popular alkyl cation, were reported by Andrei and coworkers in 2008 [8]. They found that the ethyl cation takes the nonclassical structure from both the experimental results of Ar-tagging IRPD spectra and $a b$ initio calculations. Furthermore, Reed and coworkers have recently isolated alkyl and any other cations as salts with carborane anions and characterized by X-ray crystallography [9].

However, the detailed information on the structure and electronic state of carbocation such as relative isodesmic energy, bond multiplicity, and the relative energy difference has not been fully elucidated in the past theoretical and experimental studies. Especially, systematical consideration on the detailed electronic state of alkyl cation is still needed to understand the mechanisms for several basic organic reactions and structural aspects of fundamental carbon species. The present study describes the results of theoretical investigations on the detailed structure and electronic state of 

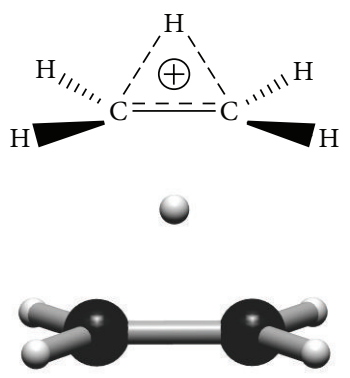

1
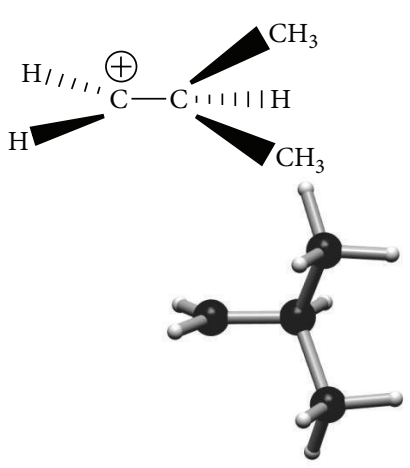

5
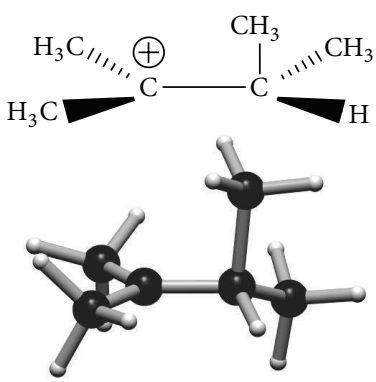

9
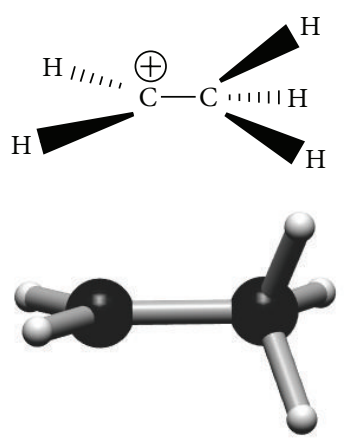

2
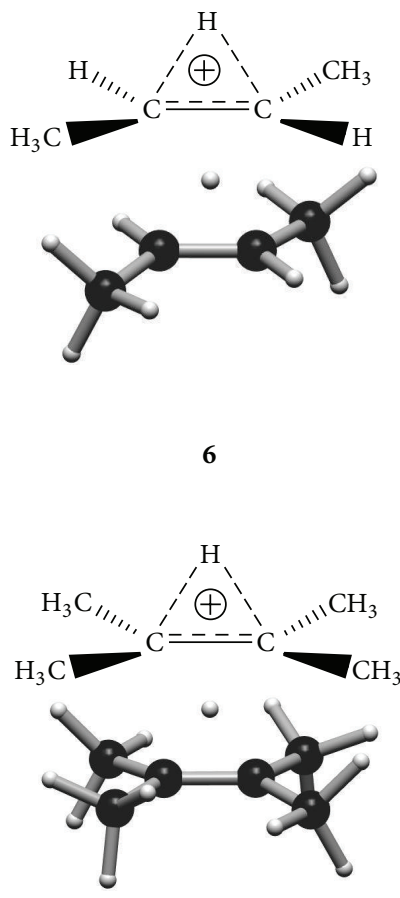

10

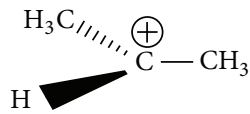<smiles>C[C+](C)C</smiles>

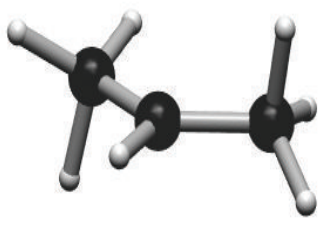

3

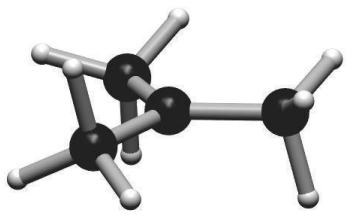

4
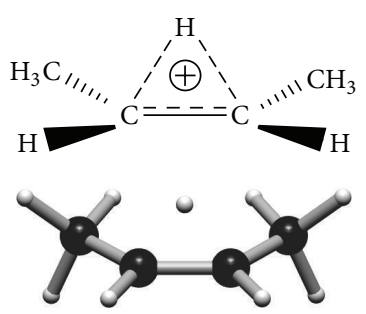

7
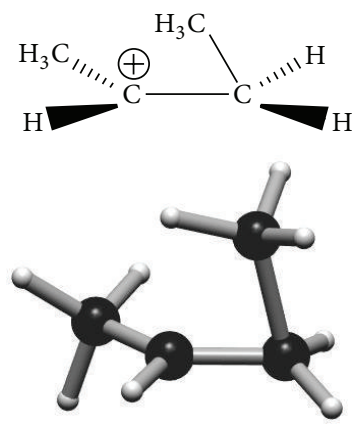

8

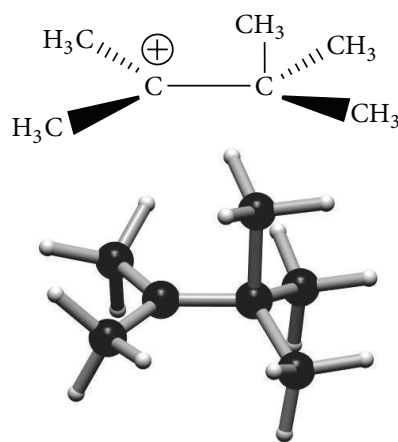

11

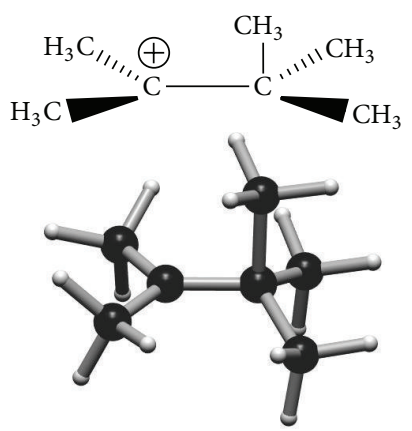

12

FIGURE 1: Optimized structures of alkyl-substituted ethyl cations at MP2/6-311+G(d,p) level of theory.

various carbocations (ethyl cation and its alkylsubstitutes) by using Møller-Plesset method.

\section{Computational Methods}

$A b$ initio theoretical calculations at second order MøllerPlesset perturbation theory (MP2) level were performed by using Gaussian 03 program for all the alkyl-substituted ethyl cations 1-11 (Table 1). First geometry optimization was performed at the B3LYP/6-31G(d) level and the optimized structure was used as an input structure for the calculation at the MP2/6-311+G(d,p) level of theory. The SCF energy, Wiberg's bond index, and compliance constant calculation for each optimized ethyl cation were verified using the same basis set, and their results were summarized in Tables 3 and 4 . The isodesmic equation and the relative reaction energy $\left(\Delta E_{\text {iso }}\right)$ were summarized in Table 5.

\section{Results and Discussions}

3.1. Calculated Molecular Structures and Molecular Orbitals of Alkyl-Substituted Ethyl Cations 1-11. The optimized structures of cations 1-11 are shown in Figure 1, and their selected bond length and angle parameters are summarized in Table 2.

Our calculations for the simplest ethyl cation by MP2 level of theory demonstrated that the cation has two energiesminimized structures (1 and 2 ) in agreement with their previous studies $[7,8]$. The cation center of optimized 2 is almost localized on one carbon atom, whereas the cation centers of $\mathbf{1}$ are splitting to two carbons (Figure 1). Therefore, the calculated structure of $\mathbf{1}$ is categorized into a nonclassical cation, while that of $\mathbf{2}$ is considered as a classical ethyl cation. The central $C^{1}-C^{2}$ bond length $(1.39 \AA)$ of nonclassical $\mathbf{1}$ is similar to that of a double bond (1.34 $\AA)$. On the other hand, 
TABLE 1: Alkyl-substituted ethyl cations 1-11.

\begin{tabular}{ccccccc}
\hline & Cation & $\mathrm{R}^{1}$ & $\mathrm{R}^{2}$ & $\mathrm{R}^{3}$ & $\mathrm{R}^{4}$ & $\mathrm{R}^{5}$ \\
\hline & $\mathbf{1}^{\mathrm{a}}$ & $\mathrm{H}$ & $\mathrm{H}$ & $\mathrm{H}$ & $\mathrm{H}$ & $\mathrm{H}$ \\
& $\mathbf{2}$ & $\mathrm{H}$ & $\mathrm{H}$ & $\mathrm{H}$ & $\mathrm{H}$ & $\mathrm{H}$ \\
& $\mathbf{3}$ & $\mathrm{Me}$ & $\mathrm{H}$ & $\mathrm{H}$ & $\mathrm{H}$ & $\mathrm{H}$ \\
& $\mathbf{4}$ & $\mathrm{Me}$ & $\mathrm{Me}$ & $\mathrm{H}$ & $\mathrm{H}$ & $\mathrm{H}$ \\
& $\mathbf{5}$ & $\mathrm{H}$ & $\mathrm{H}$ & $\mathrm{Me}$ & $\mathrm{H}$ & $\mathrm{Me}$ \\
& $\mathbf{6}^{\mathrm{a}}$ & $\mathrm{H}$ & $\mathrm{Me}$ & $\mathrm{H}$ & $\mathrm{Me}$ & $\mathrm{H}$ \\
& $\mathbf{7}^{\mathrm{a}}$ & $\mathrm{Me}$ & $\mathrm{H}$ & $\mathrm{H}$ & $\mathrm{Me}$ & $\mathrm{H}$ \\
& $\mathbf{8}$ & $\mathrm{Me}$ & $\mathrm{H}$ & $\mathrm{H}$ & $\mathrm{Me}$ & $\mathrm{H}$ \\
& $\mathbf{9}$ & $\mathrm{Me}$ & $\mathrm{Me}$ & $\mathrm{Me}$ & $\mathrm{Me}$ & $\mathrm{H}$ \\
& $\mathbf{1 0 ^ { \mathrm { a } }}$ & $\mathrm{Me}$ & $\mathrm{Me}$ & $\mathrm{H}$ & $\mathrm{Me}$ & $\mathrm{Me}$ \\
& $\mathbf{1 1}$ & $\mathrm{Me}$ & $\mathrm{Me}$ & $\mathrm{Me}$ & $\mathrm{Me}$ & $\mathrm{Me}$ \\
\hline
\end{tabular}

${ }^{\mathrm{a}}$ Nonclassical cation.

TABLE 2: Calculated structural parameters for multisubstituted ethyl cations 1-11. Selected bond lengths are in angstrom ( $\AA$ ) and selected torsion angles in degrees $\left({ }^{\circ}\right)$.

\begin{tabular}{|c|c|c|c|c|c|c|c|c|}
\hline \multirow{2}{*}{ Cation } & \multicolumn{4}{|c|}{ Bond lengths $(\AA)$} & \multicolumn{4}{|c|}{ Torsion angles $\left({ }^{\circ}\right)$} \\
\hline & $C^{1}-C^{2}$ & $\mathrm{R}^{1}-\mathrm{C}^{1}$ & $C^{2}-R^{3}$ & $C^{2}-R^{5}$ & $C^{1}-C^{2}-R^{3}$ & $\mathrm{R}^{1}-\mathrm{C}^{1}-\mathrm{C}^{2}$ & $\mathrm{R}^{1}-\mathrm{C}^{1}-\mathrm{R}^{2}$ & $\mathrm{C}^{1}-\mathrm{C}^{2}-\mathrm{R}^{5}$ \\
\hline 1 & 1.39 & 1.09 & 1.31 & 1.09 & 58.1 & 120.5 & 119.1 & 120.5 \\
\hline 2 & 1.42 & 1.09 & 1.11 & 1.11 & 106.3 & 120.1 & 116.8 & 106.3 \\
\hline 3 & 1.44 & 1.44 & 1.12 & 1.09 & 97.9 & 125.3 & 117.4 & 114.1 \\
\hline 4 & 1.46 & 1.46 & 1.11 & 1.09 & 102.7 & 119.5 & 120.7 & 113.8 \\
\hline 5 & 1.41 & 1.09 & 1.58 & 1.58 & 109.4 & 118.1 & 120.0 & 109.4 \\
\hline 6 & 1.40 & 1.09 & 1.31 & 1.49 & 58.0 & 116.5 & 118.5 & 124.8 \\
\hline 7 & 1.40 & 1.49 & 1.32 & 1.09 & 57.4 & 126.9 & 117.4 & 115.5 \\
\hline 8 & 1.41 & 1.48 & 1.66 & 1.08 & 76.2 & 124.1 & 118.2 & 118.8 \\
\hline 9 & 1.45 & 1.47 & 1.60 & 1.09 & 96.8 & 121.2 & 118.7 & 110.5 \\
\hline 10 & 1.42 & 1.50 & 1.32 & 1.50 & 57.2 & 122.4 & 115.1 & 122.5 \\
\hline 11 & 1.45 & 1.48 & 1.62 & 1.53 & 92.6 & 121.2 & 116.5 & 116.8 \\
\hline
\end{tabular}

the $\mathrm{C}^{1}-\mathrm{C}^{2}$ bond length of classical 2 is to be $1.42 \AA$. The $\mathrm{C}^{2}-\mathrm{R}^{3}$ bond lengths of $\mathbf{1}$ and 2 are envisaged to be 1.31 and $1.11 \AA$, and the bond angles of each $\mathrm{C}^{1}-\mathrm{C}^{2}-\mathrm{R}^{3}$ are 58.1 and $106.3^{\circ}$, respectively. The single point energies of each structure involving ZPE showed that nonclassical $\mathbf{1}$ is more stable than classical 2 by $1.19 \mathrm{kcal} / \mathrm{moL}$.

The gas phase structural feature of isopropyl cation 3 was also investigated by the same level of theory as $\mathbf{1}$ and $\mathbf{2}$. The $\mathrm{C}^{1}-\mathrm{C}^{2}$ bond length of the calculated 3 is $1.44 \AA$, which became shorter than that of the corresponding alkane $3-\mathbf{H}$ $(1.53 \AA)$. In case of 3 , the cation center is almost localized on the $C^{1}$ carbon. Actually, the $C^{1}-C^{2}-R^{3}$ bond angle of the calculated 3 is $97.9^{\circ}$, which is much smaller than an ideal $\mathrm{sp}^{3}$ bond angle $\left(109.3^{\circ}\right)$ due to the hyperconjugative effect from $\mathrm{C}-\mathrm{H}$ bond to the cation center. Whereas LUMO of the 2-isopropyl cation 3 is mainly formed in $\mathrm{C}^{1}$ cation center, $\mathrm{HOMO}$ is bound on the $\mathrm{C}-\mathrm{H}$ bonds of two methyl groups (Figure 2).

With respect to optimized structures of tert-butyl cation 4 and isobutyl cation 5 , the $C^{1}-C^{2}$ bond lengths are 1.46 and $1.41 \AA$ at MP2 level in the gas phase, respectively. The calculation predicted that $\mathbf{4}$ has a $C_{s}$ symmetric structure where the four carbons are coplanar $\left(\mathrm{R}^{1}-\mathrm{C}^{1}-\mathrm{C}^{2}\right.$ angle is $\left.119.5^{\circ}\right)$, and its cation center $\left(\mathrm{C}^{1}\right)$ takes almost $\mathrm{sp}^{2}$ hybridization. In fact, one $\mathrm{C}^{1}-\mathrm{C}^{2}-\mathrm{H}\left(\mathrm{R}^{3}\right)$ bond angle of the optimized 4 becomes smaller $\left(102.7^{\circ}\right)$ than that of $\mathbf{4}-\mathbf{H}\left(110.2^{\circ}\right)$. The isobutyl cation 5 possesses a classicalform, in which the cationic charge is localized on the $\mathrm{C}^{1}$ (Figure 3 ). Two methyl groups connected to the $\mathrm{C}^{2}$ are located on up and down sides of the cation plane $\left(R^{1} R^{2}-C^{1}-C^{2}\right)$, because efficient hyperconjugation from the two $\mathrm{C}-\mathrm{C}$ bonds to the cation center contributes for this conformation. The tert-butyl cation $\mathbf{4}$ is much more stable (by $>35 \mathrm{kcal} / \mathrm{moL}$ ) than 5 in gas phase, due to a strong hyperconjugative stabilization effect from three methyl groups as discussed later (Section 3.3).

A similar trend in $\mathbf{1}$ and $\mathbf{2}$ was also observed in cases of 2-butyl cations $\mathbf{6 , 7}$, and $\mathbf{8}$. Both $\mathbf{6}$ and 7 are considered as nonclassical cations because the optimized structure has almost planar framework whose cation center is splitting between $C^{1}$ and $C^{2}$. In contrast, another "kinked" form (classical cation) 8 was inferred by MP2 optimizations. LUMOs of the nonclassical cations 6 and 7 mainly exist on $C^{1}$ and $\mathrm{C}^{2}$ carbons, while they spread to the hydrogen of the "kinked" 
TABLE 3: Bond length, Wiberg's bond index (WBI), and compliance constants $\left(C_{i i}\right)$ for multisubstituted ethyl cations $\mathbf{1}, \mathbf{3}, \mathbf{6}$, and 9 and corresponding alkanes.

\begin{tabular}{lccc}
\hline Bond & Bond length $(\AA)$ & WBI & $C_{i i}(\AA /$ mdyn $)$ \\
\hline $\mathrm{C}^{1}-\mathrm{C}^{2}$ & & & \\
$(\mathbf{1})$ & 1.39 & 1.46 & 0.388 \\
$\mathbf{( 1 - H )}$ & 1.53 & 1.04 & 0.510 \\
$\mathbf{( 3 )}$ & 1.44 & 1.17 & 0.377 \\
$\mathbf{( 3 - H )}$ & 1.53 & 1.02 & 0.617 \\
$\mathbf{( 6 )}$ & 1.40 & 1.38 & 0.209 \\
$\mathbf{( 6 - H )}$ & 1.53 & 1.02 & 0.578 \\
$\mathbf{( 9 )}$ & 1.45 & 1.10 & 0.436 \\
$\mathbf{( 9 - H )}$ & 1.54 & 0.99 & 0.644 \\
$\mathrm{C}^{2}-\mathrm{R}^{3}$ & & & \\
$\mathbf{( 1 )}$ & 1.31 & 0.45 & 2.236 \\
$\mathbf{( 1 - H )}$ & 1.09 & 0.96 & 0.755 \\
$\mathbf{( 3 )}$ & 1.12 & 0.83 & 2.718 \\
$\mathbf{( 3 - H )}$ & 1.10 & 0.95 & 0.702 \\
$\mathbf{( 6 )}$ & 1.31 & 0.45 & 3.609 \\
$\mathbf{( 6 - H )}$ & 1.10 & 0.95 & 0.702 \\
$\mathbf{( 9 )}$ & 1.60 & 0.90 & 1.126 \\
$\mathbf{( 9 - H )}$ & 1.53 & 1.01 & 0.612 \\
\hline
\end{tabular}

methyl group for the classical 8. Both the central $C^{1}-C^{2}$ bond lengths of $\mathbf{6}$ (nonclassical: trans) and $\mathbf{7}$ (nonclassical: cis) are estimated to be 1.40 , whose value is almost the same as that of the classical $8(1.41 \AA)$. The $C^{2}-R^{3}(C-C)$ bond length of the classical 8 is expected to be $1.66 \AA$, which is elongated from a typical $\mathrm{C}\left(\mathrm{sp}^{3}\right)-\mathrm{C}\left(\mathrm{sp}^{3}\right)$ bond length $(1.54 \AA)$ due to the hyperconjugative effect. The $C^{1}-C^{2}-R^{3}$ bond angles of the nonclassical 6 and 7 are 57.8 and $58.1^{\circ}$, respectively, whereas the classical 8 has a larger angle $\left(76.2^{\circ}\right)$. The nonclassical 6 and 7 are estimated to be more stable than the classical 8 by 3.77 and $2.51 \mathrm{kcal} / \mathrm{moL}$, respectively, suggesting that the hyperconjugations of the methyl groups of $\mathbf{6}$ and 7 are more effective for the stabilization than that of "kinked" methyl group of $\mathbf{8}$. Moreover, the trans-nonclassical $\mathbf{6}$ is a little more stable than the cis-nonclassical 7 by $1.26 \mathrm{kcal} / \mathrm{moL}$.

The 2,3-dimethylbutyl cations 9 (classical: $1.44 \AA$ for $\mathrm{C}^{1}-$ $\mathrm{C}^{2}$ bond length, $1.60 \AA$ for $\mathrm{C}^{2}-\mathrm{R}^{3}$ bond length, and $96.8^{\circ}$ for $\mathrm{C}^{1}-\mathrm{C}^{2}-\mathrm{R}^{3}$ torsion angle) and 10 (nonclassical: $1.42 \AA$ for $\mathrm{C}^{1}-\mathrm{C}^{2}$ bond length, $1.32 \AA$ for $\mathrm{C}^{2}-\mathrm{R}^{3}$ bond length, and $57.2^{\circ}$ for $C^{1}-C^{2}-R^{3}$ torsion angle) possess the similar structural features with the ethyl and 2-butyl cations. However, our calculations revealed that classical $\mathbf{9}$ is more stable than nonclassical 10 by $8.79 \mathrm{kcal} / \mathrm{moL}$ in the gas phase. Although the reason is not clear, there is a possibility that four methyl groups of nonclassical 10 are more sterically hindered. LUMO orbital of classical 9 exists at the cation center $\left(C^{1}\right)$ and methyl groups connecting to the $\mathrm{C}^{1}$ and $\mathrm{C}^{2}$, whereas the LUMO of nonclassical 10 is almost localized on $\mathrm{C}^{1}$ and $\mathrm{C}^{2}$ carbons in a similar manner to ethyl and 2-butyl cations (Figure 3).
As a result of MP2 calculation, trimethylbutyl cation $\mathbf{1 1}$ is clearly categorized into a classical cation, because the cation center is localized on the $C^{1}$ (Figure 3). The central ethylic $\mathrm{C}^{1}-\mathrm{C}^{2}$ bond length $(1.45 \AA)$ of $\mathbf{1 1}$ is significantly shorter than that of corresponding alkane 11-H (1.55 $\AA$ ) and slightly longer than those of classical ethyl and 2-butyl cations 2 and 4 . The $\mathrm{C}^{2}-\mathrm{R}^{3}$ bond length of $\mathbf{1 1}(1.62 \AA)$ is longer than typical sp ${ }^{3}$ $\mathrm{sp}^{3}$ single bond length $(1.54 \AA)$. The $\mathrm{C}^{1}-\mathrm{C}^{2}-\mathrm{R}^{3}$ bond angle of $11\left(92.6^{\circ}\right)$ is smaller than that of corresponding alkane $\mathbf{1 - H}$ $\left(111.9^{\circ}\right)$.

\subsection{The Comparison of Structural and Bond Strength Param-} eters between Selected Cations and Their Alkanes. Structural and bond strength parameters at MP2 level calculations between cations $\mathbf{1 - 1 1}$ and corresponding alkanes $\mathbf{1 - H}-\mathbf{1 1}-\mathbf{H}$ were compared in order to estimate the hyperconjugative effect (Figure 4 and Table 3 ).

The C-C bond of ethane $\mathbf{1 - H}$ is $1.53 \AA$ in length, which should be an almost ideal $\mathrm{sp}^{3} \mathrm{C}-\mathrm{C}$ bond, whereas that of $\mathbf{1}$ generated by hydride elimination from $\mathbf{1 - H}$ becomes shorter by $0.15 \AA$ (Figure 4 ). As shown in Table 3, the compliance constant $C_{i i}$ of $C^{1}-C^{2}$ bond is changed from $0.510(\mathbf{1 - H})$ to $0.388 \AA /$ mdyn (1), indicating that the central $C^{1}-C^{2}$ bond of simple ethyl cation $\mathbf{1}$ is stronger than that of $\mathbf{1 - H}$. Such a change is attributed to the hyperconjugative effect caused by the electron transfer from $\mathrm{C}-\mathrm{H}$ covalent bond to the cation center. In contrast, the $\mathrm{C}^{2}-\mathrm{R}^{3}(\mathrm{C}-\mathrm{H})$ bond strength of cation $\mathbf{1}$ becomes much weaker than that of $\mathbf{1 - H}$ (from 0.755 to $2.236 \AA /$ mdyn), indicating that the bonding electrons of $\mathrm{C}^{2}-$ $\mathrm{R}^{3}$ are moved to the unfilled $p$ orbital (cation center). In fact, the value of Wiberg's bond index (WBI) is changed from 1.04 (1) to $1.46(\mathbf{1}-\mathbf{H})$ (Figure 3), meaning that the $C^{1}-C^{2}$ bond becomes stronger by the hydride elimination. Details of the WBIs with bond orders of the 1-11 are discussed in the following section.

The $C^{1}-C^{2}$ bond length of 2-propylcation 3 (1.44 $\AA$ ) became shorter than that of $\mathbf{3 - H}(1.53 \AA)$ by the hydride elimination (Figure 4). A similar tendency is observed for the bond strengths and WBI values of $\mathbf{3}$ and $\mathbf{3}-\mathbf{H}$. Thus, the compliance constant $C_{i i}$ of $\mathrm{C}^{1}-\mathrm{C}^{2}$ bond changed from 0.617 (1.04) to $0.377 \AA /$ mdyn (1.17). On the other hand, the $\mathrm{C}^{2}-\mathrm{R}^{3}$ bond strength of 3 became weaker (from 0.702 to $2.718 \AA /$ mdyn) from that of $3-\mathbf{H}$. Moreover, the bond angle of $C^{1}-C^{2}-R^{3}$ changed from $110.7(3-\mathbf{H})$ to $97.94^{\circ}$ (3) according to our calculations. These structural changes can also be explained by the concept of hyperconjugative effect.

Similarly, gas phase calculations predict that the ethylic $C^{1}-C^{2}$ bond of trans-2-butyl cation 5 is shorter and stronger (1.40 $\AA$ and $0.578 \AA / \mathrm{mdyn})$ than that of corresponding alkane 5-H(1.53 $\AA$ and $0.209 \AA / m d y n)$, while the $C^{2}-\mathrm{R}^{3}$ bond strength of $5(0.702 \AA /$ mdyn $)$ becomes much weaker than that of $5-\mathbf{H}$ (3.609 $\AA / \mathrm{mdyn})$ by hydride elimination.

On the other hand, MP2 level calculation in gas phase demonstrated that both 2,3-dimethylbutyl cations 8 and its hydride adduct $8-\mathbf{H}$ have the same central $C^{1}-C^{2}$ bond length (1.54 $\AA$ ). Also, accompanied by the structural change from 8 to $8-\mathbf{H}$, a decrease of $C_{i i}$ (from 0.644 to $0.436 \AA / m d y n$ ) and a 
TABLE 4: Bond orders, bond indexes, hybridizations, and occupancies parameters for multisubstituted ethyl cations 1-11.

\begin{tabular}{|c|c|c|c|c|c|c|c|c|}
\hline \multirow{2}{*}{ Cation } & \multicolumn{4}{|c|}{ Wiberg's bond indexes (NAO bond orders) } & \multicolumn{2}{|c|}{ Hybridizations } & \multicolumn{2}{|c|}{ Occupancies } \\
\hline & $C^{1}-C^{2}$ & $\mathrm{R}^{1}-\mathrm{C}^{1}$ & $C^{2}-R^{3}$ & $C^{2}-R^{5}$ & $\mathrm{C}^{1}$ & $\mathrm{C}^{2}$ & $C^{1}-C^{2}$ & $C^{2}-R^{5}$ \\
\hline 1 & $1.46(1.20)$ & $0.92(0.78)$ & $0.45(0.46)$ & $0.92(0.78)$ & $\mathrm{sp}^{2.69}$ & $\mathrm{sp}^{2.69}$ & 1.99493 & 0.69157 \\
\hline 2 & $1.23(1.06)$ & $0.95(0.77)$ & $0.84(0.75)$ & $0.84(0.75)$ & $\mathrm{sp}^{1.00}$ & $\mathrm{sp}^{3.16}$ & 1.99705 & 1.91297 \\
\hline 3 & $1.17(1.02)$ & $1.17(1.02)$ & $0.83(0.75)$ & $0.91(0.77)$ & $\mathrm{sp}^{2.32}$ & $\mathrm{sp}^{3.17}$ & 1.99051 & 1.88072 \\
\hline 4 & $1.12(0.99)$ & $1.12(0.99)$ & $0.86(0.76)$ & $0.92(0.78)$ & $\mathrm{sp}^{2.37}$ & $\mathrm{sp}^{3.21}$ & 1.98454 & 1.91306 \\
\hline 5 & $1.16(1.01)$ & $0.95(0.78)$ & $0.93(0.79)$ & $0.93(0.79)$ & $\mathrm{sp}^{2.12}$ & $\mathrm{sp}^{3.27}$ & 1.99111 & 1.91993 \\
\hline 6 & $1.38(1.16)$ & $0.91(0.77)$ & $0.45(0.47)$ & $1.05(0.91)$ & $\mathrm{sp}^{2.47}$ & $\mathrm{sp}^{2.47}$ & 1.98604 & 0.69074 \\
\hline 7 & $1.38(1.16)$ & $1.05(0.91)$ & $0.44(0.46)$ & $0.91(0.77)$ & $\mathrm{sp}^{2.90}$ & $\mathrm{sp}^{2.90}$ & 1.98649 & 0.70556 \\
\hline 8 & $1.22(1.07)$ & $1.07(0.93)$ & $0.77(0.63)$ & $1.05(0.92)$ & $\mathrm{sp}^{2.67}$ & $\mathrm{sp}^{2.13}$ & 1.98615 & 1.73687 \\
\hline 9 & $1.10(0.97)$ & $1.10(0.97)$ & $0.90(0.75)$ & $0.90(0.76)$ & $\mathrm{sp}^{2.40}$ & $\mathrm{sp}^{3.39}$ & 1.97682 & 1.88461 \\
\hline 10 & $1.32(1.13)$ & $1.03(0.90)$ & $0.43(0.46)$ & $1.04(0.90)$ & $\mathrm{sp}^{3.05}$ & $\mathrm{sp}^{3.05}$ & 1.97706 & 0.71843 \\
\hline 11 & $1.10(0.96)$ & $1.09(0.96)$ & $0.87(0.72)$ & $0.99(0.83)$ & $\mathrm{sp}^{3.05}$ & $\mathrm{sp}^{3.06}$ & 1.97307 & 1.85722 \\
\hline
\end{tabular}

TABLE 5: Total energies $E_{\text {total }}$ (Hartree) of alkyl-substituted ethyl cations 1-11 and reaction energies (kcal/mol) of corresponding isodesmic reactions ${ }^{\mathrm{a}}$.

\begin{tabular}{|c|c|c|c|c|c|c|c|c|c|}
\hline \multirow[b]{2}{*}{ Cation } & \multirow[b]{2}{*}{$\mathrm{R}^{1}$} & \multirow[b]{2}{*}{$\mathrm{R}^{2}$} & \multirow[b]{2}{*}{$\mathrm{R}^{3}$} & \multirow{2}{*}{$\begin{array}{c}+\mathrm{CH}_{4} \\
\mathrm{R}^{4}\end{array}$} & \multicolumn{2}{|c|}{$\mathrm{R}^{1}=\mathrm{R}^{3}$} & \multirow{2}{*}{$+\stackrel{\oplus}{\mathrm{C}} \mathrm{H}_{3}$} & \multirow[b]{2}{*}{$E_{\text {total }}$} & \multirow[b]{2}{*}{$\Delta E_{\text {iso }}$} \\
\hline & & & & & $\mathrm{R}^{5}$ & $E_{\text {total }}$ & & & \\
\hline 1 & $\mathrm{H}$ & $\mathrm{H}$ & $\mathrm{H}$ & $\mathrm{H}$ & $\mathrm{H}$ & -78.2804 & 1-H & -79.1823 & 31.75 \\
\hline 2 & $\mathrm{H}$ & $\mathrm{H}$ & $\mathrm{H}$ & $\mathrm{H}$ & $\mathrm{H}$ & -78.2785 & $1-\mathrm{H}$ & -79.1823 & 30.56 \\
\hline 3 & $\mathrm{Me}$ & $\mathrm{H}$ & $\mathrm{H}$ & $\mathrm{H}$ & $\mathrm{H}$ & -117.339 & $3-\mathbf{H}$ & -118.200 & 57.11 \\
\hline 4 & $\mathrm{Me}$ & $\mathrm{Me}$ & $\mathrm{H}$ & $\mathrm{H}$ & $\mathrm{H}$ & -156.380 & $4-\mathrm{H}$ & -157.220 & 70.59 \\
\hline 5 & $\mathrm{H}$ & $\mathrm{H}$ & $\mathrm{Me}$ & $\mathrm{H}$ & $\mathrm{Me}$ & -156.323 & $5-\mathrm{H}$ & -157.220 & 34.83 \\
\hline 6 & $\mathrm{H}$ & $\mathrm{Me}$ & $\mathrm{H}$ & $\mathrm{Me}$ & $\mathrm{H}$ & -156.353 & $6-\mathrm{H}$ & -157.219 & 54.28 \\
\hline 7 & $\mathrm{Me}$ & $\mathrm{H}$ & $\mathrm{H}$ & $\mathrm{Me}$ & $\mathrm{H}$ & -156.351 & $6-\mathrm{H}$ & -157.219 & 53.02 \\
\hline 8 & $\mathrm{Me}$ & $\mathrm{H}$ & $\mathrm{H}$ & $\mathrm{Me}$ & $\mathrm{H}$ & -156.347 & $6-\mathrm{H}$ & -157.219 & 50.51 \\
\hline 9 & $\mathrm{Me}$ & $\mathrm{Me}$ & $\mathrm{Me}$ & $\mathrm{Me}$ & $\mathrm{H}$ & -234.418 & 9-H & -235.251 & 74.99 \\
\hline 10 & $\mathrm{Me}$ & $\mathrm{Me}$ & $\mathrm{H}$ & $\mathrm{Me}$ & $\mathrm{Me}$ & -234.407 & 9-H & -235.251 & 68.08 \\
\hline 11 & $\mathrm{Me}$ & $\mathrm{Me}$ & $\mathrm{Me}$ & $\mathrm{Me}$ & $\mathrm{Me}$ & -273.433 & $11-\mathrm{H}$ & -274.265 & 75.61 \\
\hline
\end{tabular}

${ }^{a}$ The structural optimizations and total energies $E_{\text {total }}$ (Hartree) of methane and methyl cation were separately carried out at the same basis sets, respectively.

slight increase of bond order (from 0.99 to 1.10 ) of the $C^{1}-C^{2}$ bond were estimated by the calculation. Moreover, the $\mathrm{C}^{2}-$ $\mathrm{R}^{3}$ bond length and strength of $8(1.53 \AA$ and $0.612 \AA / \mathrm{mdyn})$ were shorter and stronger than those of $\mathbf{8}-\mathbf{H}(1.60 \AA$ and $1.126 \AA / m d y n)$, respectively. Although the hyperconjugative effect from $\mathrm{C}^{2}-\mathrm{R}^{3}$ bond to cation center of $\mathbf{8}$ is expected from the MP2 calculation, steric repulsion between the methyl groups would be inhibiting the shrinking of $C^{1}-C^{2}$ bond. The pronounced deformation of $\mathrm{C}^{1}-\mathrm{C}^{2}-\mathrm{R}^{3}$ bond angle of the cation $8\left(96.77^{\circ}\right)$ relative to alkane $8-\mathbf{H}\left(111.3^{\circ}\right)$ supports the occurrence of the steric repulsion.

3.3. NBO Analysis of the Alkyl-Substituted Ethyl Cations. Table 3 summarizes Wiberg's bond indexes (WBIs) and bond orders of ethyl cations 1-11 evaluated by the NBO analysis at MP2/6-311++G(3df,3pd) level of theory. The character of chemical bond can be intuitively understood by the use of WBI bond indexes. For example, a bond index of 1 means that the bond takes single bond.

The WBIs of nonclassical $\mathbf{1}$ and classical $\mathbf{2}$ are evaluated to be 1.46 and 1.23 , respectively, meaning that the more stable nonclassical ethyl cation $\mathbf{1}$ is essentially the same as a protonated ethylene. Actually, the NBO calculation by MP2/6-311++G(3df,3dp) level suggests that both the $C^{1}$ and $\mathrm{C}^{2}$ of 1 possess $\mathrm{sp}^{1.99}$ hybridization which is nearly equal to $\mathrm{sp}^{2}$. On the other hand, the $\mathrm{C}^{1}$ and $\mathrm{C}^{2}$ of 2 are $\mathrm{sp}^{1.55}$ and $\mathrm{sp}^{2.45}$ carbons, respectively, indicating that 2 is a classical cation.

A similar trend was also observed in 2-butyl cations 6 (trans-nonclassical), 7(cis-nonclassical), and 8 (classical) in 

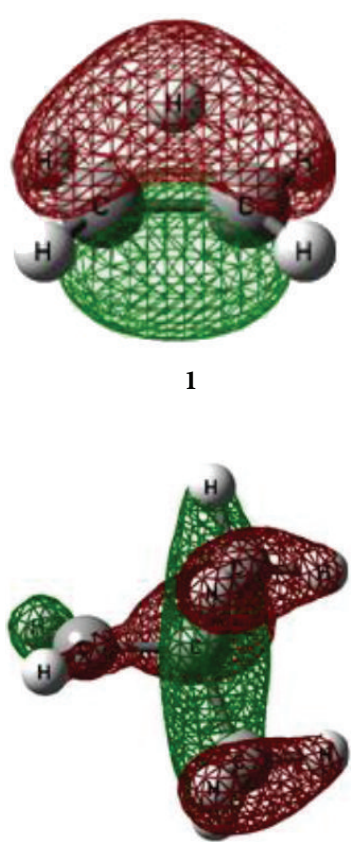

5

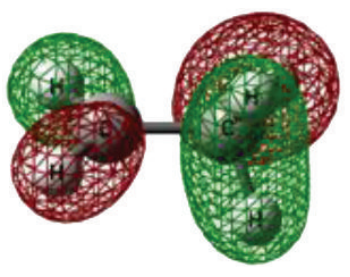

2

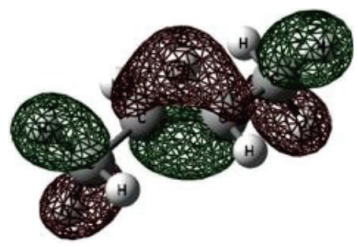

6

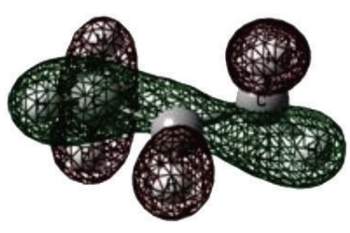

3

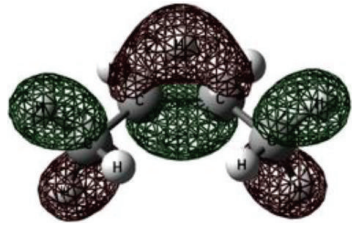

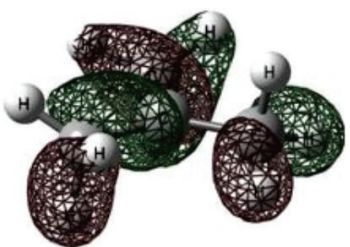

4

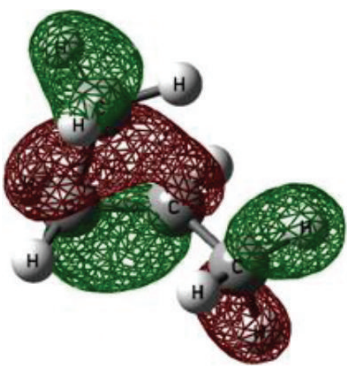

8

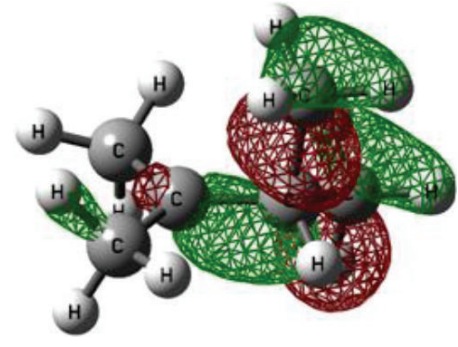

9

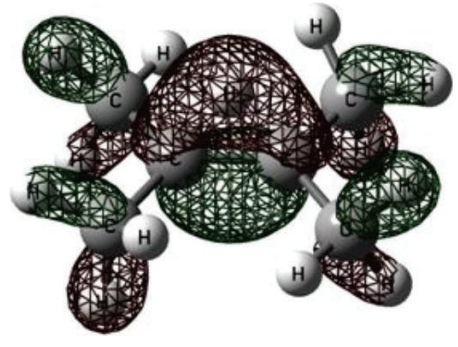

10

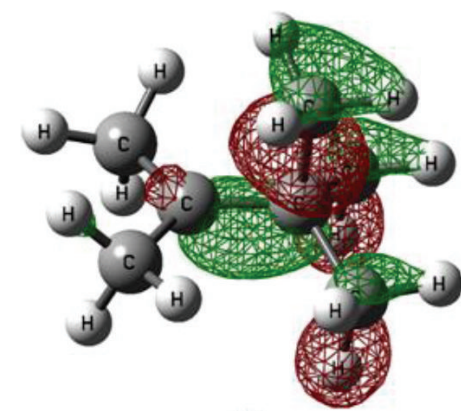

11

FIGURE 2: HOMO orbitals of ethyl cations 1-11.

the gas phase. The WBIs for $\mathbf{6 , 7}$, and $\mathbf{8}$ are $1.38,1.38$, and 1.22 , respectively. The hybridizations of $C^{1}$ and $C^{2}$ of both 6 and 7 are $\mathrm{sp}^{2.09}$ and $\mathrm{sp}^{2.08}$, while those of $\mathbf{8}$ are $\mathrm{sp}^{2.00}$ and $\mathrm{sp}^{2.26}$, respectively.

According to our calculations, the hybridizations of $\mathrm{C}^{1}$ and $\mathrm{C}^{2}$ for classical 2,3-dimethylbutyl cation 9 are provided as $\mathrm{sp}^{1.86}$ and $\mathrm{sp}^{2.51}$, respectively. On the other hand, both of them were $\mathrm{sp}^{1.86}$ for nonclassical 2,3-dimethylbutyl cation 10 by $\mathrm{NBO}$ calculation in the gas phase. The bond order and bond index of central ethylic $\mathrm{C}^{1}-\mathrm{C}^{2}$ bond for $\mathbf{1 0}$ are 0.96 and 1.10 , respectively.

Our calculations revealed that the hybridization values of central $\mathrm{C}^{1}$ and $\mathrm{C}^{2}\left(\mathrm{sp}^{1.77}\right.$ and $\left.\mathrm{sp}^{2.66}\right)$ of the trimethylbutyl cation $\mathbf{1 1}$ are also close to those of $\mathbf{9}$ (Table 4 ).

3.4. Total Energies and Hydrogen Affinities of Each Cation. The zero point corrected total energies [ $E_{\text {total }}$ 's] of alkylsubstituted ethyl cations and their isodesmic reaction energy
$\left[\Delta E_{\text {iso }}\right]$ by MP2/6-311++G(3df,3dp) level are summarized in Table 5.

Each $\Delta E_{\text {iso }}$ is derived from the difference of total energies between alkane plus methyl cation and alkyl cation plus methane according to the equation shown in Table 5. The difference of $\Delta E_{\text {iso }}\left(\Delta \Delta E_{\text {iso }}\right)$ between nonclassical ethyl cation 1 and classical cation 2 is $1.19 \mathrm{kcal} / \mathrm{moL}$. The gas phase MP2 calculation revealed that the hydride affinity of the $t$-butyl cation 3 is considerably lower than that of simple ethyl cation by $38-40 \mathrm{kcal} / \mathrm{moL}$. This fact means that the tert-butyl cation 3 is much more stable than ethyl, propyl, and other butyl cations.

2-Methylpropan-1-yl cation 5 with a similar stability to ethyl cation is less stable than tert-butyl cation 4 $(35.8 \mathrm{kcal} / \mathrm{moL})$. In case of 2-butyl cations, both the nonclassical cations 5 and $\mathbf{6}$ possess almost the same isodesmic reaction energy $\left(\Delta E_{\text {iso }}=54.28 \mathrm{kcal} / \mathrm{moL}\right.$ for 5 and $53.02 \mathrm{kcal} / \mathrm{moL}$ for 6 ) in the gas phase. On the other hand, 


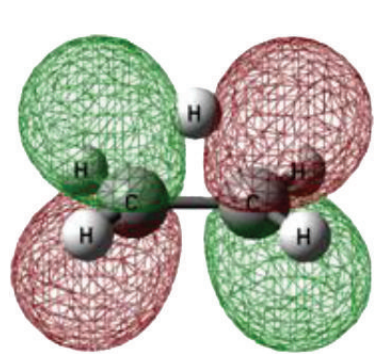

1

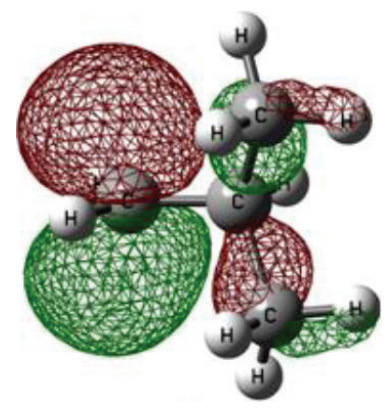

5

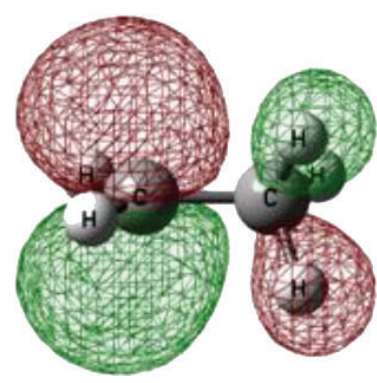

2

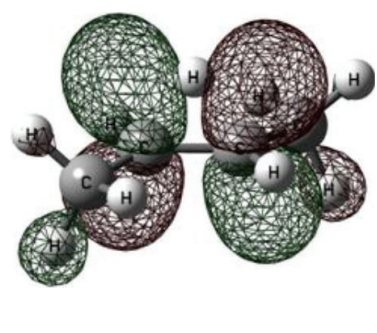

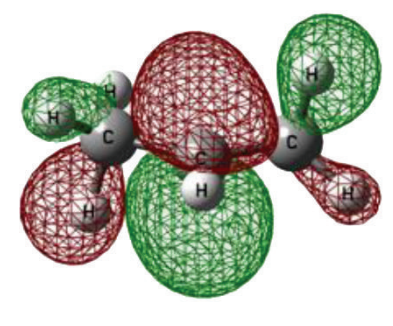

3

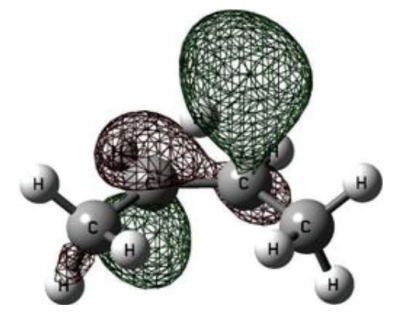

7

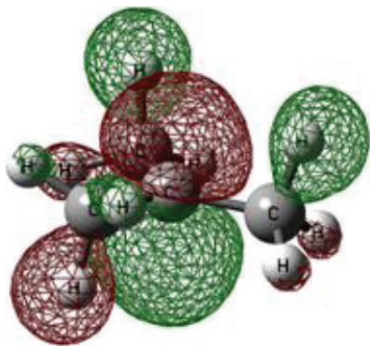

4

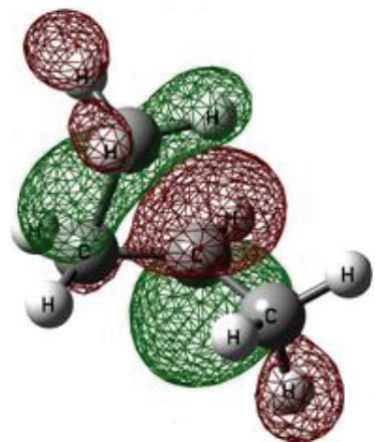

8

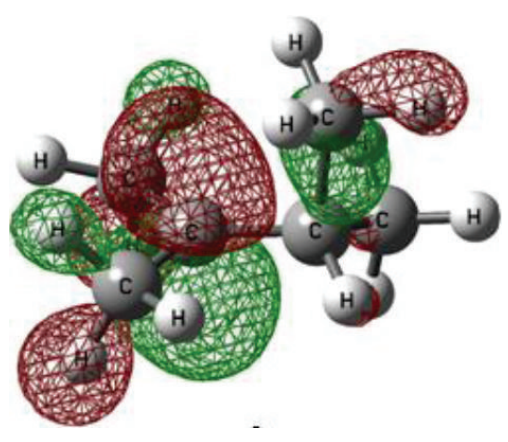

9

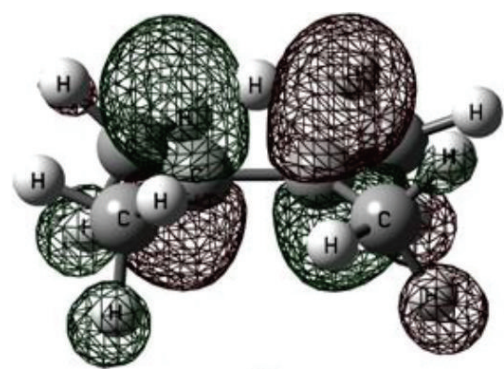

10

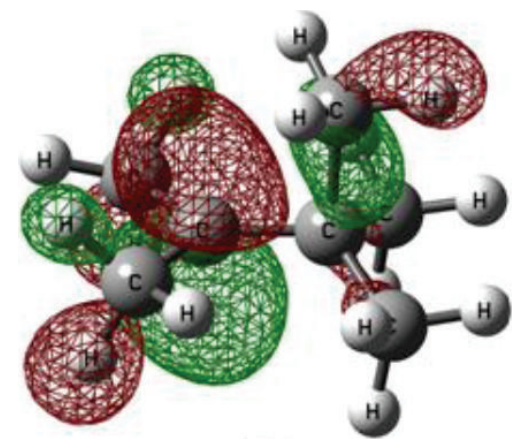

11

FIgURE 3: LUMO orbitals of ethyl cations 1-11.

MP2 calculations revealed that classical 7 is less stable than nonclassical 5 and 6 by $3 \mathrm{kcal} / \mathrm{moL}$.

Although nonclassical ethyl and butyl cations are more stable than the corresponding classical cations, classical and nonclassical 2,3-dimethylbutyl cations $\mathbf{9}$ and $\mathbf{1 0}$ showed an opposite trend $\left(\Delta \Delta E_{\text {iso }}=6.91 \mathrm{kcal} / \mathrm{moL}\right)$. That classical 9 is more stable than nonclassical 10 is attributed to a higher steric repulsion between four methyl groups in $\mathbf{1 0}$ with a shorter $\mathrm{C}^{1}-\mathrm{C}^{2}$ bond length than the corresponding alkane.

Tetramethylbutyl cation $\mathbf{1 1}$ had the highest gas phase isodesmic reaction energy $\left(\Delta E_{\text {iso }}=75.61 \mathrm{kcal} / \mathrm{moL}\right)$, indicating the most stable cation among a series of alkyl-substituted ethyl cations in this report.

\section{Conclusions}

Gas phase structural and electronic properties of alkyl-substituted ethyl cations 1-11 were investigated at MP2 level.
It was revealed that there are nonclassical and classical forms for ethyl, 2-butyl, and 2,3-dimethylbutyl cations, whose nonclassical cationic state is more stable than the classical one (1.19 and $3.48 \mathrm{kcal} / \mathrm{moL})$. On the contrary, the calculation for 2,3-dimethylbutyl cation demonstrated that the classical cation is more stable by $8.79 \mathrm{kcal} / \mathrm{moL}$ than the nonclassical one. The WBI parameters of the central $\mathrm{C}^{1}-\mathrm{C}^{2}$ bonds for the nonclassical and classical cations were 1.32-1.46 and 1.101.23 multiplicities in the gas phase, respectively. It was estimated from compliance constant $C_{i i}$ that the $C^{1}-C^{2}$ bonds for the nonclassical cations are stronger than those of the classical cations, while the former $C^{2}-R^{3}$ bonds are weaker than the latter ones due to the hyperconjugative effects. The gas phase hydride affinities based on isodesmic equations demonstrated that the nonclassical cations are strongly stabilized by electron donations from $\mathrm{C}^{2}-\mathrm{R}^{3}$ bond. In case of 2,3-dimethylbutyl cations, however, the classical cation 

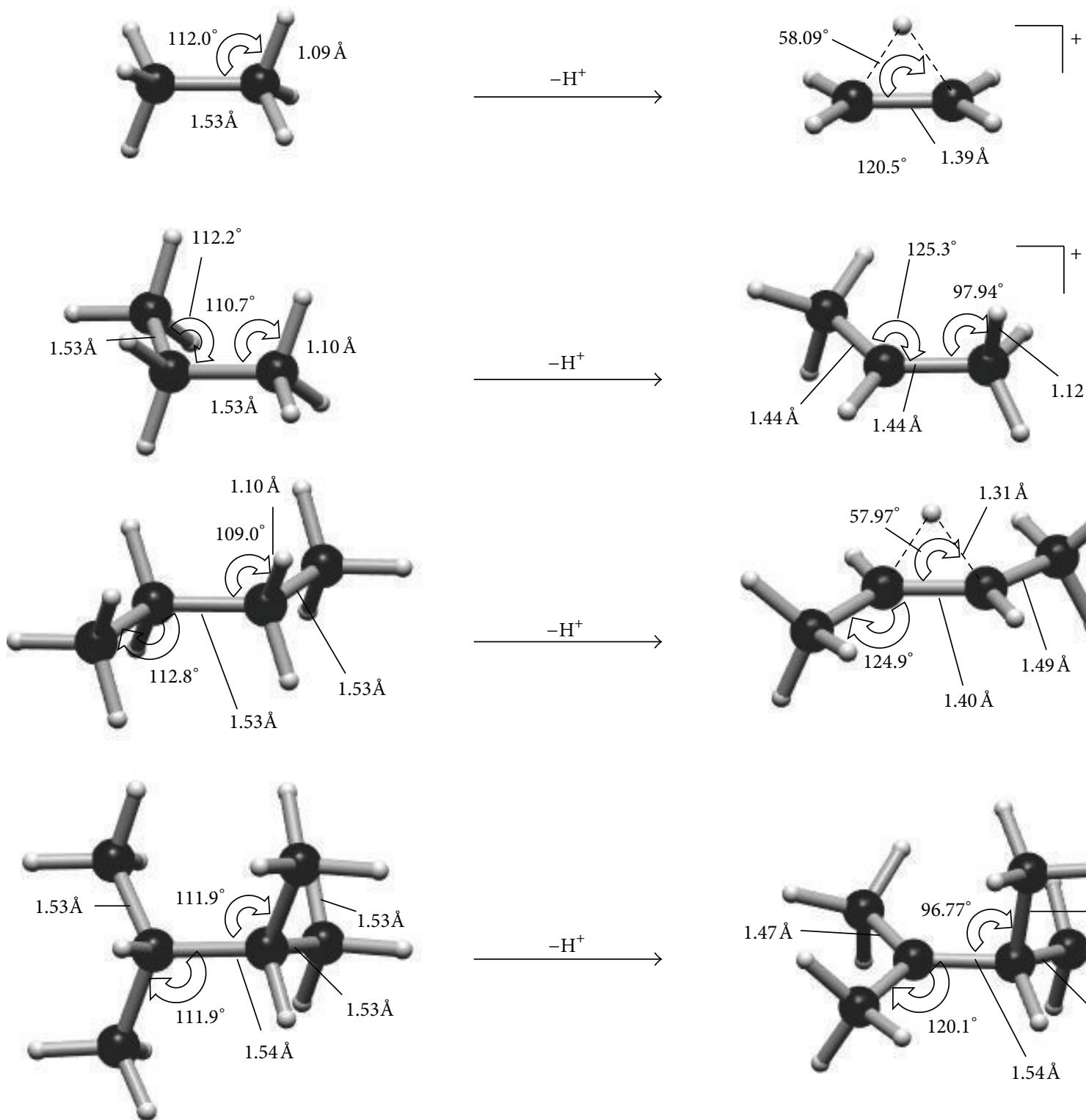

FiguRE 4: Structural comparisons between alkyl-substituted ethyl cations 1, 3, 5, and 9 and their alkanes calculated by MP2/6-311+G(d,p) level of theory.

was predicted to be more stable than nonclassical one by $8.79 \mathrm{kcal} / \mathrm{moL}$ due to the steric repulsions between four methyl groups substituted on the $\mathrm{C}^{1}$ and $\mathrm{C}^{2}$ carbons.

\section{References}

[1] G. A. Olah, "Crossing conventional boundaries in half a century of research," Journal of Organic Chemistry, vol. 70, pp. 24132429, 2005.

[2] P. R. Von Schleyer, W. E. Watts, R. C. Fort Jr., M. B. Comisarow, and G. A. Olah, "Stable carbonium ions. X. Direct nuclear magnetic resonance observation of the 2-norbornyl cation," Journal of the American Chemical Society, vol. 86, no. 24, pp. 5679-5680, 1964.

[3] C. S. Yannoni, R. D. Kendrick, P. C. Myhre, D. C. Bebout, and B. L. Petersen, "The geometry of reactive intermediates by nutation NMR spectroscopy: the tert-butyl cation," Journal of the American Chemical Society, vol. 111, no. 16, pp. 6440-6442, 1989.

[4] D. Fărcaşiu, S. H. Norton, and D. Hâncu, "Theoretical studies of carbocations in ion pairs. 5. structures and interconversion of the 3-methyl-2-butyl cation and 2,3-dimethyl-1-protonated cyclopropane," Journal of the American Chemical Society, vol. 122, pp. 668-676, 2000.

[5] D. Fărcaşiu and S. H. Norton, "Secondary and tertiary 2methylbutyl cations. 3. theoretical study of structures and interconversions of $\mathrm{C}_{5} \mathrm{H}_{11}^{+}$ions in the gas phase ${ }^{1 a}$," Journal of Organic Chemistry, vol. 62, pp. 5374-5379, 1997.

[6] A. M. Ricks, G. E. Douberly, P. V. R. Schleyer, and M. A. Duncan, "Infrared spectroscopy of protonated ethylene: the nature of proton binding in the non-classical structure," Chemical Physics Letters, vol. 480, no. 1-3, pp. 17-20, 2009. 
[7] H. Feng, W. Sun, Y. Xie, and H. F. Schaefer III, "Structures and energetics of the tert-butyl cation: the final answer or a neverending story?" Chemistry, vol. 17, no. 38, pp. 10552-10555, 2011.

[8] H.-S. Andrei, N. Solc, and O. Dopfer, "IR spectrum of the ethyl cation: evidence for the nonclassical structure," Angewandte Chemie International Edition, vol. 47, pp. 395-397, 2007.

[9] C. A. Reed, "Carborane acids. New "strong yet gentle" acids for organic and inorganic chemistry," Chemical Communications, no. 13, pp. 1669-1677, 2005. 

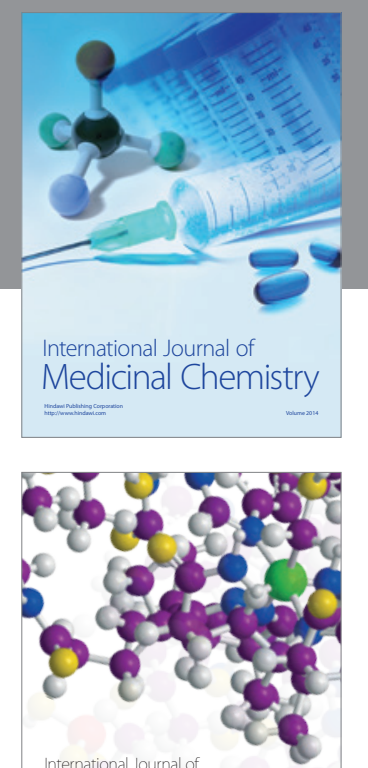

\section{Carbohydrate} Chemistry

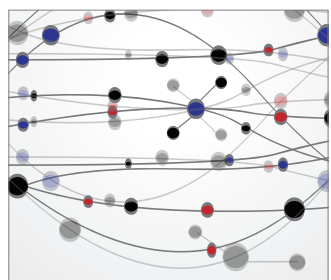

The Scientific World Journal
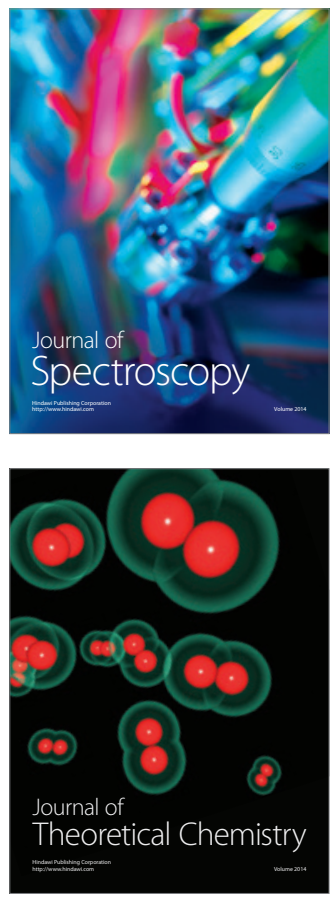
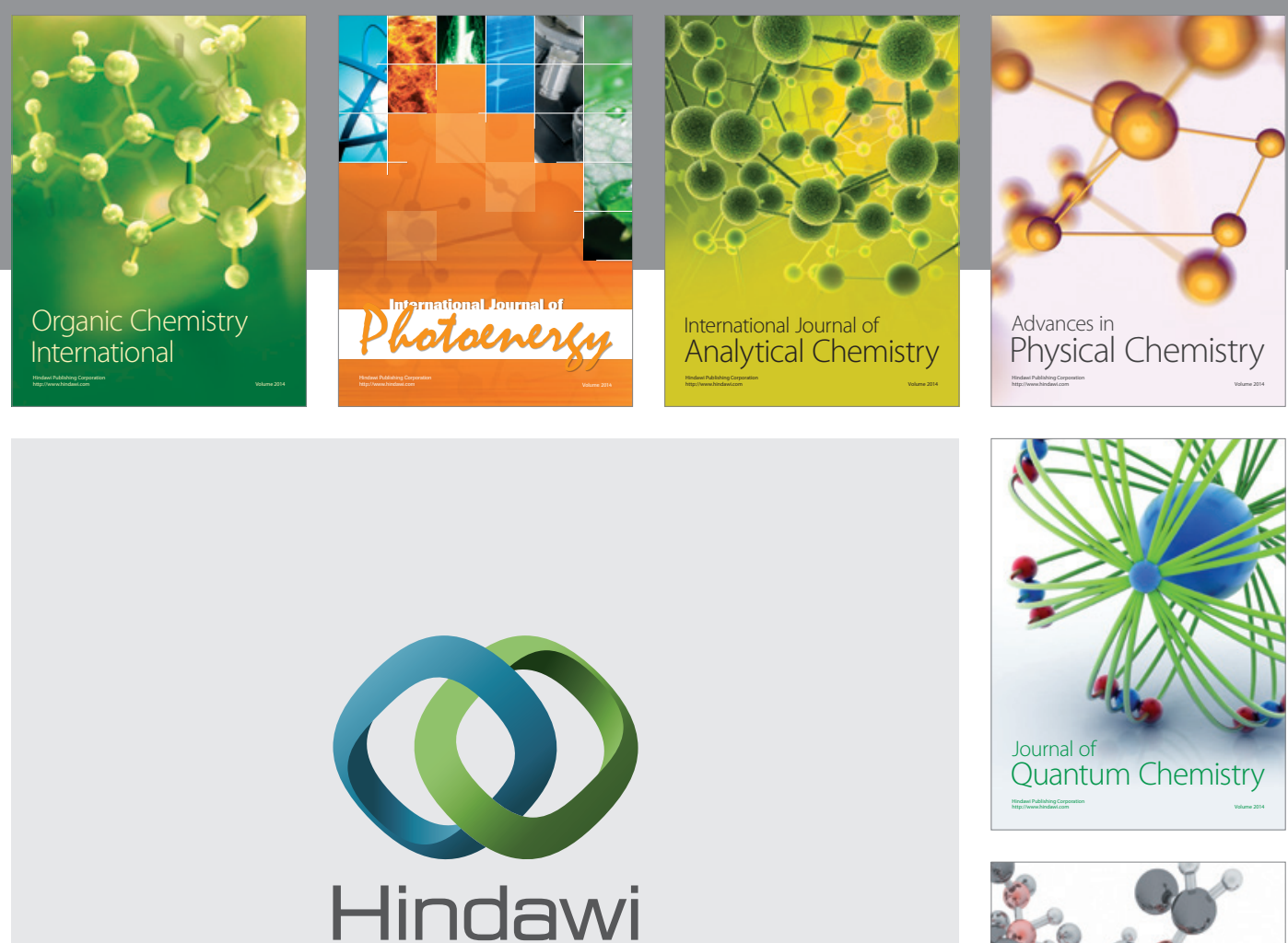

Submit your manuscripts at

http://www.hindawi.com

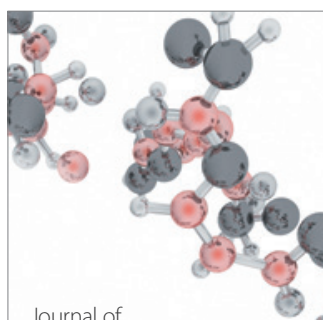

Analytical Methods

in Chemistry

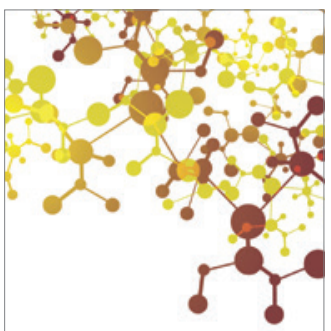

Journal of

Applied Chemistry

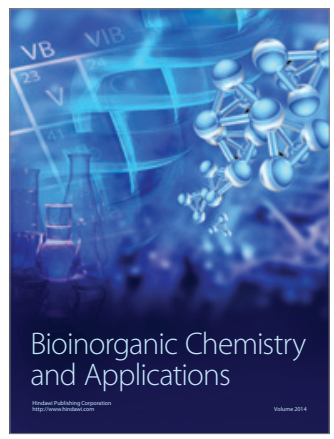

Inorganic Chemistry
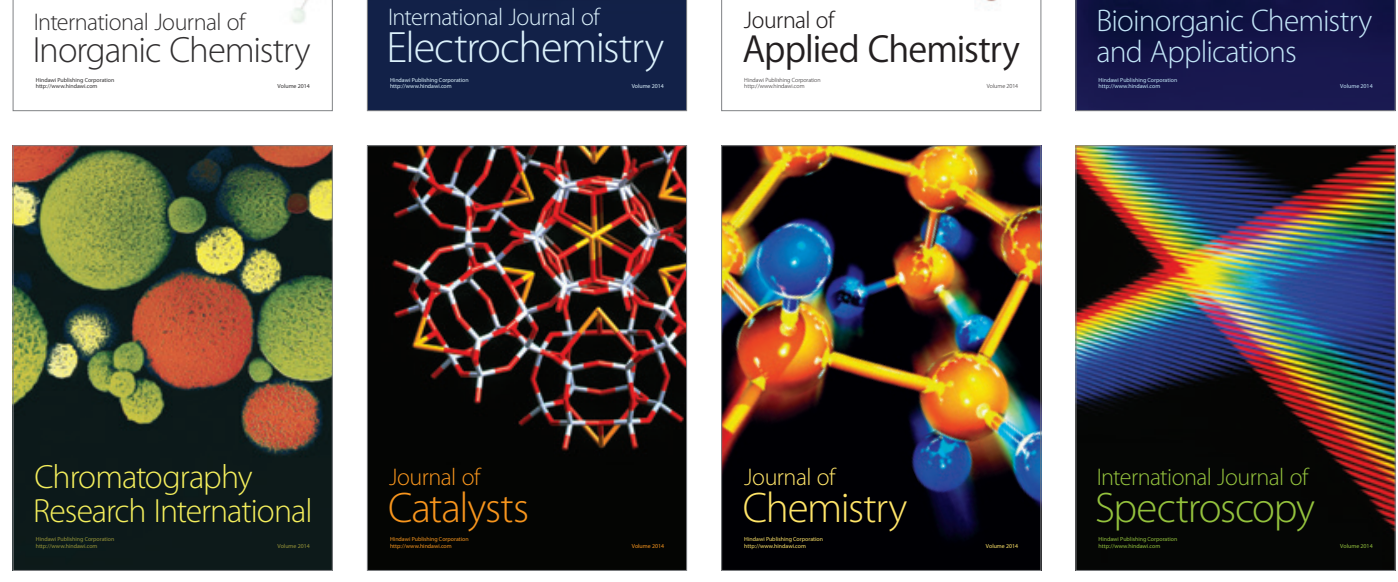